\title{
The Medical Devices Special Access Program in Canada: A Scoping Study
}

\section{Programme canadien d'accès spécial aux instruments médicaux : étude de l'étendue}

\author{
ROLAND K. MAIER, BSC, MLT \\ Graduate Student \\ School of Public Health, University of Alberta \\ Edmonton, $A B$ \\ DEVIDAS MENON, PHD, MHSA \\ Professor, Health Technology and Policy Unit \\ School of Public Health, University of Alberta \\ Edmonton, $A B$ \\ TANIA STAFINSKI, MSC, PHD \\ Director, Health Technology and Policy Unit \\ School of Public Health, University of Alberta \\ Edmonton, $A B$
}

\begin{abstract}
New health technologies enter Canadian healthcare organizations in various ways, and understanding them is essential to the development of a pan-Canadian Health Technology Management (HTM) Strategy, now a priority of governments across Canada. One way is through Health Canada's Medical Devices Special Access Program (MDSAP), which permits unlicensed devices to be obtained by healthcare professionals. However, the circumstances around and implications of the current use of this program are not clear. A scoping literature review was conducted to clarify these and identify important roles and issues related to the MDSAP. Limited information was found on the MDSAP. Nevertheless, three themes demonstrating the roles of the MDSAP in HTM emerged: arbiter in technology selection, a route to technology procurement and facilitator of health technology innovation.
\end{abstract}


No information suggesting that MDSAP is used to circumvent licensing was found. Rather, it enables desired patient outcomes and product commercialization.

\section{Résumé}

Les nouvelles technologies de la santé font leur entrée dans les organismes de santé de plusieurs façons qu'il est essentiel de comprendre pour le développement d'une stratégie pancanadienne pour la gestion des technologies de la santé (GTS), laquelle est devenue une priorité pour les gouvernements au Canada. Un des chemins d'entrée de ces technologies est le programme d'accès spécial aux instruments médicaux (PASIM) de Santé Canada, qui permet aux professionnels de la santé d'avoir accès à des instruments non homologués. Toutefois, les circonstances et les répercussions de l'usage actuel du programme ne sont pas claires. Ainsi, une revue de la littérature a été menée pour clarifier ces questions et déterminer les rôles et enjeux importants liés au PASIM. Peu d'informations ont été trouvées sur le PASIM. Néanmoins, trois thèmes se sont dégagés pour démontrer les rôles du PASIM dans la GTS : un arbitre pour le choix d'une technologie, une route pour l'obtention d'une technologie et un facilitateur d'innovation dans les technologies de la santé. Aucune information suggérant que le PASIM est employé pour éviter l'homologation n'a été trouvée. Il aide plutôt à atteindre les résultats souhaités pour les patients ainsi que la commercialisation d'un produit.

Lthough healthcare organizations across Canada have made significant
progress in developing health technology assessment (HTA) systems, there has
been growing concern that their capacity to better manage health technology, more broadly, is lacking. In December 2016, the Federal/Provincial/Territorial Conference of Deputy Ministers of Health tasked the Canadian Agency for Drugs and Technologies in Health (CADTH) to propose a pan-Canadian health technology management (HTM) strategy. HTM extends beyond HTA, and essentially involves the management of a health technology through its life cycle (research and development, HTA, adoption, use and disinvestment). According to the 2017-2018 Business Plan of CADTH, one priority initiative is the transition of CADTH to an HTM enterprise, which is "an organization that supports real-world decision-making at all levels, monitors drug and non-drug utilization over the technology lifecycle, and supports implementation at the policy and practice levels" (CADTH 2017).

HTM requires knowledge of how new health technologies enter organizations. A recent survey of 47 healthcare organizations across Canada revealed a variety of mechanisms, one of which was the MDSAP (Report to Health Canada, funded through a Contribution Agreement \#6804-15-2013/10810069; Stafinski et al. 2017). Other mechanisms include piloting (providing a technology for a fixed number of cases) and clinical trials under protocol; neither of these involves the SAP process. 
The MDSAP is laid out in Part 2 of the Canadian Medical Devices Regulations under the Food and Drugs Act - Custom-Made Devices and Medical Devices Imported or Sold for Special Access (defined as "access to a medical device for emergency use or if conventional therapies have failed, are unavailable or are unsuitable") (Government of Canada 1985, 1998b; McAllister and Jeswiet 2003; Gibson and Lemmens 2015). While the program has existed for almost 20 years, how it has been perceived and used remain unclear.

The objective of this study was to determine the landscape of information related to the MDSAP in Canada using scoping review methodology, and gain insights into its role in HTM.

\section{Methods}

The scoping study approach (initially developed in 2005 by Arksey and O'Malley) was selected because it is ideally suited to situations where the field of evidence is anticipated to be small and when a wide range of research and non-research material needs to be consulted (Anderson et al. 2008; Davis et al. 2009; Levac et al. 2010). It consists of an iterative design with up to six stages.

\section{Stage 1 - Identify the research question}

The study question was developed iteratively while simultaneously keeping in constant focus the underlying aims of the review (Mays et al. 2005). Because the overall aim was to understand broadly what scholarly work had been done to date, and what the sources, volume and types of information were, the research question was defined as, "What is known from the existing literature about Health Canada's Medical Devices Special Access Program (MDSAP)?"

\section{Stage 2 - Identify relevant studies}

The search for relevant material was not limited to peer-reviewed sources, as the research purpose was to capture the breadth and range of information available. A list of keywords was developed iteratively, and a search strategy developed with the assistance of an information specialist. For peer-reviewed references, 13 electronic bibliographic databases were searched. A number of approaches to searching the grey literature were attempted with Google Scholar providing the most fruitful results. Links within web pages were also explored.

Searches were conducted between April 2015 and December 2017 (see Appendix 1, available at: https://www.longwoods.com/content/25398).

\section{Stage 3 - Select studies}

As recommended by Levac et al. (2010), the broad research question was then "[combined] with a clearly articulated scope of inquiry in order to guide the search strategy and establish parameters around study selection and data extraction." Inclusion and exclusion criteria were developed post hoc and were applied to all material by two reviewers. Material was considered in-scope if it related directly to Health Canada's MDSAP, including custom-made devices accessed through 
the program. Conversely, material was considered out-of-scope if it did not meet the inclusion criteria. Topics that were explicitly identified as being out of scope included:

- programs from other countries;

+ $\quad$ special access programs for drugs or biologics (e.g., blood products);

+ investigational trials access;

+ healthcare delivery programs;

- off-label use (when a technology has received marketing approval for one indication but is used for another indication); or

+ reimbursement mechanisms.

Press releases, patents, book chapters and non-English material were also excluded.

Importantly, the quality of the material was not formally assessed and did not form a basis for exclusion.

\section{Stage 4 - Chart the data}

A standardized form was developed to record extracted information (see Appendix 2, available at: https://www.longwoods.com/content/25398). Two reviewers independently pilot-tested the form prior to full use. It contained two sections: one for general data (type and purpose of document, location, date of publication, authorship and sponsorship or affiliation disclosure) and one for specific data about medical devices (device name, type, and manufacturer; dates and quantities used) where these were provided.

\section{Stage 5 - Collate, summarize and report the results}

Two separate "maps" were produced (Davis et al. 2009). The first, a literature map, characterized the range and depth of literature. The second, a device map, compiled the MDSAP-authorized medical devices found in the literature and categorized them by medical specialty using the Preferred Name Code classification system used by Health Canada (Health Canada 2006)

In addition to these two mapping constructs, a thematic analysis using open coding based on first impressions of the data (Saldana 2012) and synthesis was conducted, which yielded a concept map (Attride-Stirling 2001; Gale et al. 2013; Thomas and Harden 2008).

\section{Stage 6 - Consult expert opinion}

A subject matter expert consultation exercise was conducted. In stable contexts such as the health management field, relevant stakeholders are often "visible" (Varvasovsky and Brugha 2000), and the aim in selecting stakeholders is to secure competencies rather than to assure representativeness of all possible interest groups (Welp et al. 2006). Accordingly, individuals with extensive background in regulatory affairs and Health Canada's MDSAP were required. A representative from the medical devices industry and a regulator were consulted. 
The subject matter experts were presented with background information on study rationale, methods and preliminary findings, and were asked to consider the completeness of the literature search and to identify additional references (Levac et al. 2010). No respondent identified any additional resources.

\section{Results}

\section{Literature map}

A total of 173 documents were retrieved (see Appendix 3, available at: https://www. longwoods.com/content/25398).

\section{Medical device map}

No single source of information comprehensively listed the names of all medical devices obtained through the MDSAP. Information published by Health Canada was limited to national aggregate numbers of device applications processed annually (Health Canada 2013,2014).

Fifty-three devices were identified, although some devices had more than one associated manufacturer or vendor because of corporate mergers and acquisitions. Forty-one of these devices were in the cardiovascular category (see Appendix 4, available at: https://www. longwoods.com/content/25398).

\section{Literature themes}

Most of the peer-viewed papers that were found focused on individual technologies, and not on the MDSAP, which was frequently referenced only as the means to obtain access to the unlicensed technology. However, basic themes still emerged, and were categorized into organizing themes and then into "global" themes. The resulting concept map contained the following three global themes described below (Figure 1).

THEME \# 1: THE MDSAP AS AN ARBITER IN HEALTH TECHNOLOGY SELECTION, PLAYING AN “APPROVAL” ROLE

\subsection{APPROVAL IS FOR PATIENTS AND CLINICAL INDICATIONS}

The MDSAP provides approval for the patient as an individual, not patients in aggregate or at the population level, and is described as having "a single patient focus" (Health Canada 2007). "... all patients received approval to have surgery from Health Canada on the Special Access Program ..." (Pop et al. 2002). In addition, small batches of devices for multiple individuals may be approved on a case-by-case basis (Health Canada 2014).

Many authors indicated that patient eligibility was dependent upon the clinical indication (Amat-Santos et al. 2015; Basmadjian et al. 2016; Campelo-Parada et al. 2016; Chu et al. 2016; de Varennes et al. 2016; Gonzalez-Barlatay et al. 2017; Peters 2002; RodésCabau et al. 2010; Sapp et al. 2013; Saw et al. 2015, 2017; Webb et al. 2006). Peters (2002) explained that MDSAP "provides approval for the use of silicone gel implants for the following patients: mastectomy, augmentation after failed saline implants (usually with ripples and 
folds) and primary augmentation if a saline failure is strongly predicted. Health Canada has not approved the use of gel implants for general use." More recently, de Varennes et al. (2016) reported that "These cases were not 'run-of-the-mill' AVRs [aortic valve replacements]. Health Canada would not have authorized us to use a valve in that setting."

FIGURE 1. Concept map derived through thematic synthesis of the literature

\begin{tabular}{|c|c|}
\hline & $\begin{array}{l}\text { The MDSAP as an arbiter in } \\
\text { health technology selection }\end{array}$ \\
\hline & $\begin{array}{l}\text { HC reviews patients } \\
\text { - Age of patient } \\
\text { - elderly patient } \\
\text { - pediatric patient } \\
\text { - Condition of patient } \\
\text { - high-risk } \\
\text { - co-morbidities } \\
\text { - esthetics }\end{array}$ \\
\hline & $\begin{array}{l}\text { HC reviews techniques } \\
\text { - Procedure itself } \\
\text { - Associated procedures } \\
\text { - during intervention } \\
\text { - for patient selection } \\
\text { - for measuring outcomes }\end{array}$ \\
\hline & $\begin{array}{l}\text { HC reviews devices } \\
\text { - Use of device } \\
\text { - Licensed alternatives } \\
\text { - Custom device }\end{array}$ \\
\hline- & $\begin{array}{l}\text { HC approves moral applications } \\
\text { - Compassionate use } \\
\text { - Patient consent } \\
\text { - Ethics } \\
\text { - institutional review board } \\
\text { - hospital panel review } \\
\text { - Physician discretion }\end{array}$ \\
\hline$L$ & $\begin{array}{l}\text { HC approves evidence-based } \\
\text { applications } \\
\text { - Unique criteria } \\
\text { - SAP devices vs. SAP drugs } \\
\text { - SAP devices vs. licensing or ITA } \\
\text { - Low evidence threshold } \\
\text { - no long-term outcome data } \\
\text { - Subjective criteria } \\
\text { - open to interpretation }\end{array}$ \\
\hline
\end{tabular}

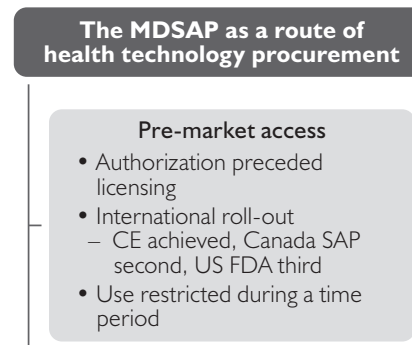

\section{Non-market access}

- Clinical trials not possible

- incremental changes

- unethical

- Market size too small

- Custom-made devices

- Circumvention

\section{Logistics}

- Forms and instructions

- individual request

- batch request

- Labelling requirements

- Application processing

- speed

- high volume of requests

" rejection

- Compliance and enforcement

- Advertising

- Sale

- decision letters

- distribution records

- product return

Costs
- Application fees
- Technology costs
- cost-effectiveness
- device cost
- societal costs

The MDSAP as a facilitator of health technology innovation

Technology introduction

- Technical feasibility

- procedural success

- efficacy

- effectiveness

- performance

- safety

- Short-term outcomes data

- Physician as pioneer

- First-in-human use

\section{Technology evolution}

- Generation of device - physical design change

- New clinical indication for existing device

- off-label use

- New technique for existing devices

Technology routinely used

- Increased volume of requests

- Batch requests

- Institutional protocols

- Additional manufacturer with similar product

Technology learning curve

- Physician competency

- experience

- Patient suitability

- Registry for data collection

and dissemination

- Mid-term outcomes data

- Long-term outcomes data

CE = European Conformity; FDA = Food and Drug Administration; HC = Health Canada; ITA = investigational trial access; MDSAP = Medical Devices SAP; $\mathrm{SAP}=$ Special Access Program.

\subsection{APPROVAL IS FOR TECHNIQUES AND PROCEDURES}

Regarding percutaneous aortic valve implantation, Webb et al. (2006) wrote, "The procedure was approved by the Therapeutic Products Directorate, Department of Health and Welfare, Ottawa, Canada, for compassionate clinical use ..."

Further examples include needle ablation (Sapp et al. 2013), left atrial appendage closure (Regueiro et al. 2017; Saw et al. 2015) and left atrial decompression (Amat-Santos et al. 2015). Some authors attributed approval of not only a procedure but also an entire program to the MDSAP. "In 2005, the Canadian TAVI [transcatheter aortic valve implantation] 
program was approved by the Department of Health and Welfare (Ottawa, Ontario, Canada) for compassionate clinical use ..." (Rodés-Cabau et al. 2010).

\subsection{APPROVAL IS FOR DEVICES}

The MDSAP approves the use of unlicensed alternatives to licensed medical devices when they are perceived to be clinically superior (Almashham et al. 2008; Abraham et al. 2012; Bagur et al. 2016; Campelo-Parada et al. 2016; Humpl et al. 2010; Nietlispach et al. 2010; Raymond et al. 2001; Regueiro et al. 2017; Ricci et al. 2017; Saw et al. 2017). Peters' (2002) review of breast implants noted the availability of two types of implants: saline-filled (comprising 95\% of implants), which were licensed, and gel-filled (5\%), which, at the time, were unlicensed. Gel-filled implants were being used for "patients with exceptional circumstances, who received approval on compassionate grounds, because the quality of their final results would be more compromised with saline implants ... than with gel implants."

The uniqueness of the device (Is it sufficiently different from a licensed alternative?) was a consideration in approval. Minor variations in design and incremental improvements were considered insufficient for granting approval (Health Canada 2016).

The MDSAP also approves custom-made devices (Government of Canada 1998b; Health Canada 2016). Two examples are custom-made endovascular stents (Lioupis et al. 2012; Mewhort et al. 2011; Nietlispach et al. 2010) and a custom-made device for atrial septal defect closure (Gonzalez-Barlatay et al. 2017).

\subsection{APPROVAL DEPENDS UPON MORAL JUDGMENTS}

"Compassionate use" was noticeably absent in government documents, but in primary studies, justification for MDSAP approval often related to compassion (Cheung et al. 2010; Cheung et al. 2014). Ricci et al. (2017) stated that the MDSAP was intended to offer treatment "in a patient population that had no other therapeutic option."

The requirement for patient consent is found in the "Undertaking" section of the application form. However, Health Canada has recognized that it has no jurisdictional authority in this area, because patient consent is established in the physician-patient relationship, and regulated at the provincial/territorial level through colleges of medicine (Government of Canada 2007). Soon et al. (2011) wrote, "The prosthesis was approved for compassionate use by the department of Health and Welfare, Ottawa, Canada, in consenting patients declined for conventional reoperative surgery." Similarly, Gurvitch et al. (2010) wrote, "All patients were approved on a compassionate-use basis and gave written informed consent."

Institutional review was not a requirement for approval, but was mentioned as being sought in select cases (Basmadjian et al. 2016; Chu et al. 2017; Del Trigo et al. 2016a). Asch (2002) noted, "In cases in which it was deemed that filter removal had to be postponed beyond 12 weeks for a medical indication, specific approval from both the ethics department and the Health Protection Branch was sought and granted." The requirement for approval from all three parties was noted by Dahdah et al. (2007). "Given the investigational 
status of the device used in this case report, approval was obtained from an institutional government-designated pediatric ethics committee and from the Canadian Special Access Programme of the Therapeutic Products Directorate, Health Canada. Parental written informed consent was obtained prior to the intervention."

\subsection{APPROVAL DEPENDS UPON EVIDENCE ADEQUACY}

Approval depends upon satisfying minimum evidence requirements as defined by Health Canada. Its Special Access Unit, with scientific reviewers and medical experts in the Bureau, decides on authorization based on the medical rationale provided and other information available (Health Canada 2016). These evidence requirements are unique to the MDSAP because of their separate position (in Part 2) within the Medical Devices Regulations. A number of documents described this evidentiary uniqueness through comparisons with other programs.

Health Canada (2007) noted: "Separate regulatory provisions for drugs and devices have created inconsistencies between two programmes even though they have the same overarching intention, namely to provide emergency use access to products unavailable on the Canadian market." Walker et al. (2014) concluded that many jurisdictions have "a lower evidentiary standard for devices compared to drugs."

Two articles compared the denial of a request for AIDS drugs with the approval of requests for breast implants and argued that there was less evidence of benefit to breast implant recipients (cosmetic) than there was to AIDS drug recipients (life-saving) (Christie and Montaner 2006; Government of Canada 2006b).

Differences in evidence requirements for investigational testing, licensing and obtaining devices via special access were also raised. As indicated by Health Canada, "Medical devices authorized under Special Access do not undergo the same level of scrutiny required to obtain a medical device license or an authorization for investigational testing" (Health Canada 2016).

Evidence thresholds were seen as being open to interpretation. A report of the Standing Committee on Health captured this sentiment with a committee member's question, "So I am wondering how you can determine that the risk is acceptable and therefore offer breast implants to all these women without having any long-term studies?" (Government of Canada 2005b).

\section{THEME \# 2: THE MDSAP AS A ROUTE OF HEALTH TECHNOLOGY PROCUREMENT}

\subsection{PRE-MARKET ACCESS}

The MDSAP provided an early route for professionals to access unlicensed products which subsequently were licensed, e.g., the Thermablate ${ }^{\text {TM }}$ endometrial ablation technology (Vilos and Edris 2007) and the product Bio-Alcamid ${ }^{\mathrm{TM}}$ (Ellis and Sardesai 2008). Both were first used through MDSAP before receiving regulatory approval. More recently, Health Canada has stated that although the SAP plays a role by providing access to products that have not yet obtained market authorization (Health Canada 2007), it is not intended as an "early market access" route for devices that are still in trials, still in development or awaiting licensure (Health Canada 2016). However, the rapid increase in the number of requests 
to the MDSAP in recent years (see Section 2.3 below) may suggest its use as a mechanism for achieving early market access.

However, the MDSAP does appear to play a role in commercialization based on the sequential licensing of a device at an international level. The product may have been licensed in one jurisdiction and obtained via special access before receiving market approval in Canada or an additional jurisdiction. The Amplatzer Plug III (a CE-marked device) was accessed via MDSAP in Canada while under evaluation by the Food and Drug Administration in the US (Jilaihawi and Ibrahim 2010). A second example was the international roll-out of Thermablate, initially approved for sale by the State Drug Administration in China and also used to treat 54 women in Canada via the MDSAP before it received licensing. Approval for sale in Europe with CE marking followed (Yackel and Vilos 2004).

A variation of the pre-market access concept was the case of silicone gel implants, whereby the products were initially licensed, then withdrawn from the market and obtained only by SAP and later marketed again after additional studies had demonstrated the products were safe (Brown et al. 2005; Hall-Findlay 2011; Spear and Hedén 2007).

\subsection{NON-MARKET ACCESS}

Certain devices obtained through the MDSAP have never been licensed in Canada. Accumulating the clinical evidence needed for market approval is sometimes seen as an insurmountable barrier. For heart valves, Webb et al. (2010) explained, "It is unlikely that we will see rigorous testing of all potential combinations of available surgical and transcatheter valve types, frames configurations, and sizes." Interventions to treat rare diseases are also difficult to evaluate through clinical trials, because of the small number of patients (Walker et al. 2014). Custom-made devices are also challenging to evaluate for efficacy because each device is designed specifically for one individual (Klepinski 2006; Lioupis et al. 2012).

Also, Canada represents a small potential market (e.g., the CE-labelled Innogenetics Inno-LIA HIV I/II Score, an unlicensed assay, can only be obtained through the SAP [Kadivar et al. 2013]).

\subsection{LOGISTICS}

The logistics of procurement were described in several papers, including Health Canada's recently issued Guidance document (Health Canada 2016). Collectively, they provide information relevant to manufacturers, importers and healthcare professionals on topics such as: applicant qualifications, individual and batch requests, advertising, labelling, purchasing and sale, return of unused products, etc., within the context of the MDSAP.

The volume of SAP requests is also a logistics issue. In 2004, the Auditor General's report stated: "In 2002, Health Canada received 5,000 requests through the Special Access Program, a 683 percent increase in the last four years. Since the staff who process requests through the Special Access Program are the same as those who conduct pre-market evaluations, time spent dealing with these requests is time taken away from working on pre-market 
evaluations" (Government of Canada 2004). Health Canada (2016) similarly advised, "the Special Access Unit experiences a high volume of requests and follow-up communications," and the Therapeutic Products Directorate's annual performance reports drew attention to the application processing metrics of the MDSAP (Health Canada 2013; Health Canada 2014).

\subsection{COSTS}

The two relevant types of costs associated with the MDSAP are program costs and device costs. Devices being requested through MDSAP are exempt from application fees on the basis of the determination that "these devices have been exempted ... for public good reasons" (Government of Canada 1998a). It is not clear how institutions pay for them, but Health Canada has offered guidance on two matters: (1) devices do not have to be provided free of charge by the manufacturer and (2) cost savings of the device are not an adequate justification for granting access (Health Canada 2016). Only one study of cost-effectiveness of a device being acquired by SAP was found in the literature (Hancock-Howard et al. 2013).

Walker et al. (2014) discussed the cost of these devices to society from an ethical standpoint. "Potential cost burdens to society are difficult to predict as the funding implications of SAPs vary by location and program. Where health care payment systems are structured around evidence of safety, efficacy, and cost-effectiveness, SAPs have the potential to open the door to costly and unproven interventions, thereby subverting attempts to contain costs based on sound reasoning and evidence. Supplying unproven interventions entails opportunity costs; manufacturers may not develop alternative options and governments have less to spend on more effective interventions."

\section{THEME \#3: THE MDSAP AS A FACILITATOR OF HEALTH TECHNOLOGY INNOVATION}

\subsection{TECHNOLOGY INTRODUCTION}

The MDSAP enables access to emerging technologies (Government of Canada 2004; Health Canada and the Public Health Agency of Canada 2014; Health Canada 2016; Osten et al. 2010; Sinclair et al. 2013; Webb et al. 2006).

Several papers discussed technical feasibility, safety, procedural success rate, efficacy or short-term patient outcomes, all key information elements for technology uptake and diffusion (e.g., Chu et al. 2017; Helton et al. [2011] and Purdham et al. [2012] on cardiac valves; de Hemptinne et al. 2017; Saw et al. 2017). Health Canada has acknowledged the importance of publishing studies that report on such elements to communicate findings to the relevant clinical community (Health Canada 2016).

The MDSAP has also been used to facilitate first-in-man-use applications of devices for patients "who would otherwise have no clinical options" and were given "careful scrutiny" (Health Canada 2016). In 2005, during meetings of the Standing Committee on Health, the program was portrayed as providing access, with the healthcare professional described as the initiating force or the technology pioneer (Government of Canada 2005a, 2005b). 


\subsection{TECHNOLOGY EVOLUTION}

The MDSAP provides access to evolving technologies (evolution of the device or of its use). In several papers, device evolution was phrased in the language of "generations," such as the third-generation HeartWare HVAD (Rao et al. 2013), second-generation endometrial ablation technologies (Vilos and Edris 2007) or second-generation transcatheter aortic valve (Bagur et al. 2016) or in terms of improvement or evolution in time (Purdham et al. 2012; Stein and Stein 2014; Velasco-Sanchez et al. 2013). Device evolution was expressed in terms of novel techniques or additional clinical indications. For example, Osten et al. (2010) described how TAVI evolved from an antegrade transvenous transseptal approach to percutaneous retrograde transfemoral and anterograde transapical approaches. Occasionally, off-label use was reported as being intertwined with special access use: "The use of CSs [covered stents] in this study were obtained as an off-label application through a special-access government medical programmer [sic] (Kundu et al. 2011)." However, Health Canada distinguishes between the two and provides oversight of off-label use through the Investigational Testing provisions of Part 3 of the regulations (Health Canada 2016).

\subsection{TECHNOLOGY ROUTINELY USED}

The MDSAP can influence the path of a technology to routine use. In some cases, after the first MDSAP approval, requests for the device have accelerated, as its adoption became more widespread. TAVI was one of the most documented technologies accessed through the MDSAP in Canada, its use rising exponentially as it became well-established for treating select patients (Del Trigo et al. 2016b; Jilaihawi et al. 2012). Silicone breast implants experienced a large increase in use in Ontario between 2000 and 2005 as plastic surgeons gained confidence in their safety (Snell et al. 2008).

Health Canada's position on the general use of devices obtained via SAP is that healthcare facilities should not expect to obtain individual devices on an ongoing basis, and that SAP approval does not suggest that the device is appropriate or suitable for general use (Health Canada 2016). However, batch requests for devices routinely required in urgent, life-threatening circumstances are available on a case-by-case basis (Health Canada 2014).

\subsection{TECHNOLOGY LEARNING CURVE}

Many non-drug health technologies are associated with learning curves, of which an important component is appropriate patient selection (Zamorano et al. 2011). This is reported as being particularly true with MDSAP devices (Chu et al. 2017; Ricci et al. 2017; Soon et al. 2011; Wong et al. 2010). The MDSAP has advised that, where device training is required prior to use, the timing of training prior to submitting the SAP application should be considered (Health Canada 2016).

Once devices are accessed, there is limited monitoring (Government of Canada 2006a). To assist with the collection of outcomes data about specific new technologies, a number of registries have been created (Cribier and Zajarias 2008; Guerrero et al. 2015; Purdham et al. 2012). 
Some papers referred to the MDSAP in terminology associated with research, such as the "Canadian special access trial" and "Canadian special access study" (Del ValleFernández et al. 2010; Hancock-Howard et al. 2013). Other research-oriented articles noted that the device was initially obtained via special access, and then became licensed. "During the initial portion of this study, the PED was only available through a Health Canada compassionate-use program (O'Kelly et al. 2013)."

\section{Limitations}

The limitations of this study include its reliance upon publicly available sources. There are two potential implications of this: (1) incompleteness of the medical devices identified and (2) over-representation of emerging technology and technology adoption themes, because of the nature of the research articles reviewed.

\section{Discussion}

The three global themes of technology selection, procurement and innovation determined through the scoping review suggest that the MDSAP is one mechanism of HTM in Canada. In most cases, medical devices adopted by health systems have received regulatory approval from Health Canada. However, based on the findings of the review, many enter the same systems each year through the MDSAP. Because HTM takes a life cycle approach, the MDSAP, therefore, becomes an important consideration.

Diffusion of innovations starts from individual use cases, where authorizations are granted on ethical grounds after assessment of safety, effectiveness and risk/benefit for individuals. While the MDSAP is not intended to be an early market access route for medical devices, it involuntarily plays that role. As additional authorized requests for the emerging technology continue to build the evidence base, a critical mass is reached that permits (or disqualifies) device licensing and marketing. This decision is now no longer made on the basis of optimal care for an individual, but on the ethical grounds of safety and effectiveness at the population level.

Thus, the special access program does not appear to be used to circumvent licensing and sale for general (population) use. The MDSAP allows an emerging or evolving technology to demonstrate that it has promise and gather support and momentum. Where evidence is limited, the healthcare professional bridges the evidence gap by providing the medical rationale to Health Canada on the application form. This enables ethically desired patient outcomes as well as product commercialization.

The findings from this scoping review suggest that the MDSAP may be an effective commercialization strategy for industry. By providing education and training in the use of new technologies to physician pioneers, industry has a commercialization route available for cases in which clinical trial data are difficult to obtain. Bates (2008) investigated similar programs in the pharmaceutical context, known in Europe as "named patient programmes," and provided evidence that these programs were effective in increasing market share.

The review identified a number of evidence gaps and, in turn, areas for future research. They include investigating the magnitude and level of significance of the MDSAP in Canada. 
To what extent does it shape the healthcare landscape - in which medical specialties or for which diseases? What is the health economic impact? It might be useful to take a different methodological approach (cf. a scoping review, such as this) to this, utilizing surveys and interviews of clinicians and industry representatives to get a deeper understanding of the SAP processes. Of note, in the area of custom-made devices, very little information is currently publicly available. Concept maps stratified by stakeholder groups should also be developed. The special access program is a unique federal route with a different mandate than the standard licensing route. Are the unique circumstances, opportunities and risks surrounding special access devices sufficiently understood at the provincial and territorial level? At the institutional level? And, as Bryan et al. (2014) implore, are they optimally managed?

\section{Conclusion}

This paper provides the first scoping review and analysis of publicly available information pertaining to the Canadian Medical Devices Special Access Programme. Because this route appears to be a preferred one for the early introduction of innovative and rapidly evolving medical devices, it is important to understand it in the context of developing a pan-Canadian HTM approach. Such an approach would require the review of devices along their life cycles, and not just at the entry phase. The MDSAP may provide a means of early study of such devices, with subsequent studies being conducted as the device evolves (e.g., to second and third generations) or the understanding of its characteristics and functionalities become more evident. The MDSAP may provide the opportunity to generate evidence on early use, and permit the modification of policy regarding its continued utilization.

\section{Acknowledgements}

We gratefully acknowledge the contributions provided by the subject matter experts during the consultative exercise in Stage 6. However, this paper does not claim to represent any reviewer's position. Responsibility for the content and conclusions of this study resides with the authors. We are also grateful to Leigh-Ann Topfer and Lynn Lacombe-Robinson for support with the literature searches.

Correspondence may be directed to: Roland K. Maier, School of Public Health, University of Alberta, 3021, Research Transition Facility, 8308-114 Street NW, Edmonton, AB T6G 2V2; tel.: 780-802-6892; fax: 780-248-1546; e-mail: rkmaier@ualberta.ca.

\section{References}

Abraham, R.J., A.J. Illyas, T. Marotta, P. Casey, B. Vair and R. Berry. 2012. "Endovascular Exclusion of a Splenic Artery Aneurysm Using a Pipeline Embolization Device." Journal of Vascular and Interventional Radiology 23(1): 131-35. doi:10.1016/j.jvir.2011.09.015.

Almashham, Y., N. Dahdah and J. Miro. 2008. "Use of Radiofrequency then Stent Implantation for Recanalization of Complete Aorta Coarctation." Pediatric Cardiology 29(1): 207-09. doi:10.1007/ s00246-007-9090-2. 
Amat-Santos, I.J., S. Bergeron, M. Bernier, R. Allende, H.B. Ribeiro, M. Urena et al. 2015. “Left Atrial Decompression through Unidirectional Left-to-Right Interatrial Shunt for the Treatment of Left Heart Failure: First-In-Man Experience With the V-Wave Device." EuroIntervention 10(9): 1127-31. doi.10.4244/EIJY14M05_07.

Anderson, S., P. Allen, S. Peckham and N. Goodwin. 2008. "Asking the Right Questions: Scoping Studies in the Commissioning of Research on the Organisation and Delivery of Health Services." Health Research Policy and Systems 6(1): 7. doi:10.1186/1478-4505-6-7.

Arksey, H. and L. O'Malley. 2005. “Scoping Studies: Towards a Methodological Framework." International Journal of Social Research Methodology 8(1): 19-32. doi:10.1080/1364557032000119616.

Asch, M.R. 2002. "Initial Experience in Humans with a New Retrievable Inferior Vena Cava Filter," Radiology 225(3): 835-44. doi:10.1148/radiol.2252011825.

Attride-Stirling, J. 2001. “Thematic Networks: An Analytic Tool for Qualitative Research.” Qualitative Research $1(3): 385-405$.

Bagur, R., P.J. Teefy, B. Kiaii, D. Diamantouros and M.W. Chu. 2016. “First North American Experience with the Transfemoral ACURATE-neoTM Self-Expanding Transcatheter Aortic Bioprosthesis." Catherterization and Cardiovascular Interventions 90: 130-38.

Basmadjian, L., A. Basmadjian, L.-M. Stevens, F.-P. Mongeon, R. Cartier, N. Poirier and I. El Hamamsy. 2016. "Early Results of Extra-Aortic Annuloplasty Ring Implantation on Aorric Annular Dimensions." Journal of Thoracic and Cardiovascular Surgery 151(5): 1280-85.e1.

Bates, A.K. 2008. "Implementing a Pre-Launch Named Patient Programme: Evidence of Increased Market Share." Journal of Medical Marketing: Device, Diagnostic and Pharmaceutical Marketing 8(4): 319-24. doi:10.1057/jmm.2008.25.

Brown, M.H., R. Shenker and S.A. Silver. 2005. "Cohesive Silicone Gel Breast Implants in Aesthetic and Reconstructive Breast Surgery." Plastic and Reconstructive Surgery 116(3): 768-79. doi:10.1097/01. prs.0000176259.66948.e7.

Bryan, S., C. Mitton and C. Donaldson. 2014. "Breaking the Addiction to Technology Adoption." Health Economics 23(4): 379-83. doi:10.1002/hec.3034.

CADTH. 2017. CADTH 2017-2018 Annual Business Plan. Retrieved December 10, 2017. <https://www. cadth.ca/sites/default/files/pdf>.

Campelo-Parada, F., A. Regueiro, E. Dumont, R. DeLarochelliére, J.-M. Paradis, S. Mhammadi et al. 2016.

"Embolic Protection in Patients Undergoing Transaortic Transcatheter Aortic Valve Replacement: Initial Experience with the TriGuard HDH Embolic Deflection Device". Journal of Caridac Surgery 31: 617-22.

Cheung, A., J.K.F. Hon, J. Ye and J. Webb. 2010. “Combined Off-Pump Transapical Transcatheter Aortic Valve Implantation and Minimally Invasive Direct Coronary Artery Bypass." Journal of Cardiac Surgery 25(6): 660-62. doi:10.1111/j.1540-8191.2010.01081.x.

Cheung, A., J. Webb, S. Verheye, R. Moss, R. Boone, J. Leipsic et al. 2014. “Short-Term Results of Transapical Transcatheter Mitral Valve Implantation for Mitral Regurgitation." Journal of the American College of Cardiology 64(17): 1814-19. doi:10.1016/j.jacc.2014.06/1208.

Christie, T.K.S. and J.S.G. Montaner. 2006. "The Perverted Irony of Health Canada's Special Access Programme." Canadian Medical Association Journal 174(12): 1746.

Chu, M.W., R. Bagur, P. Diamontouros, P.J. Teefy and B. Kiaii. 2016. “Early Clinical Outcomes with a Novel Self-Expanding Aortic Bioprosthesis in Patients at Higher Risk for Coronary Obstruction: First North American Experience with the ACURATE-AT System." Canadian Journal of Cardiology 32(10) (Supp.1), S237.

Chu, M.W., R. Bagur, K.L. Losenno, P.M. Jones, P. Diamontouros, P. Teefy et al. 2017. “Early Clinical Outcomes of a Novel Self-Expanding Transapical Transcatheter Aortic Valve Bioprosthesis." Journal of Thoracic and Cardiovascular Surgery 153(4): 810-18.

Cribier, A. and A. Zajarias. 2008. "Transcatheter Aortic Valve Replacement: The Future is Here!" Revista Española de Cardiología 61(11): 1123-25. 
Dahdah, N., R. Ibrahim and L. Cannon. 2007. "First Recanalization of a Coronary Artery Chronic Total Obstruction in an 11-Year-Old Child with Kawasaki Disease Sequelae using the CROSSER Catheter." Pediatric Cardiology 28(5): 389-93. doi:10.1007/s00246-006-0083-3.

Davis, K., N. Drey and D. Gould. 2009. "What are Scoping Studies? A Review of the Nursing Literature." International Journal of Nursing Studies 46(10): 1386-400. doi:10.1016/j.ijnurstu.2009.02.010.

de Hemptinne, Q., E.M. Horlick, M.D. Osten, X. Millan, V.-X. Tadros, M. Pighi et al. 2017. "Initial Clinical Experience with the GORE ${ }^{\circledR}$ CARDIOFORM ASD Occluder for Transcatheter Atrial Septal Defect Closure." Catheterizaion and Cardiovascular Interventions 90: 495-503.

de Varennes, B., K. Lachapelle, R. Cecere, I. Szczepkowski and J. Buithieu. 2016. “North American SingleCenter Experience with a Sutureless Aortic Bioprosthesis." Journal of Thoracic and Cardiovascular Surgery 151(3): 735-42. doi:10.1016/j.jtcvs.2015.10.064.

Del Trigo, M., S. Bergeron, M. Bernier, I.J. Amat-Santos, R. Puri, F. Campelo-Parada et al. 2016a.

"Unidirectional Left-to-Right Interatrial Shunting for Treatment of Patients with Heart Failure with Reduced Ejection Fraction: A Safety and Proof-of-Principle Cohort Study." Lancet 387: 1290-96.

Del Trigo, M., A. Dahou, J.G. Webb, D. Dvir, R. Puri, O.A. Altisent et al. 2016b. “Self-Expanding Portico Valve Versus Balloon-expandable SAPIEN XT Valve in Patients With Small Aortic Annuli: Comparison of Hemodynamic Performance." Revista Española de Cardiología (English Edition) 69: 501-08. doi:10.1016/j. rec.2015.08.019.

Del Valle-Fernández, R., C.A. Martinez and C.E. Ruiz. 2010. "Transcatheter Aortic Valve Implantation." Cardiology Clinics 28(1): 155-68. doi:10.1016/j.ccl.2009.09.002.

Ellis, D. and M.G. Sardesai. 2008. "Bio-Alcamid: An Alternative to Fat Transfer." Facial Plastic Surgery Clinics of North America 16(4): 429-33. doi:10.1016/j.fsc.2008.05.002.

Gale, N.K., G. Heath, E. Cameron, S. Rashid and S. Redwood. 2013. “Using the Framework Method for the Analysis of Qualitative Data in Multi-Disciplinary Health Research." BMC Medical Research Methodology 13(1): 117.

Gibson, S. and T. Lemmens. 2015. "The Promise and Peril of Adapting the Regulatory System to the Pharmacogenomic Context." McGill Journal of Law and Health 8(2): S145-S230.

Gonzalez-Barlatay, F., A. Fournier, M.-J. Raboission and N. Dahdah. 2017. "Atrial Septal Defect Closure with Occlutech $^{\otimes}$ ASD Fenestrated Device in a Child with Severe Pulmonary Hypertension." Pediatric Cardiology 38: 202-05.

Government of Canada. 1985. Food and Drugs Act (R.S.C. 1985. c. F-27). Retrieved January 31, 2017. <http:// laws-lois.justice.gc.ca/eng/acts/F-27/index.html>.

Government of Canada. 1998a. Canada Gazette Part I. Vol. 132, No. 24. Ottawa, ON. Retrieved January 28, 2017. <http://publications.gc.ca/gazette/archives/p1/1998/1998-06-13/pdf/g1-13224.pdf>.

Government of Canada. 1998b. Medical Devices Regulations (Consolidation) SOR/98-282. Retrieved September 2, 2016. <http://laws-lois.justice.gc.ca/PDF/SOR-98-282.pdf>.

Government of Canada. 2004. March 2004 Report of the Auditor General of Canada: Chapter 2 - Health Canada Regulation of Medical Devices. Retrieved September 4, 2016. <http://www.oag-bvg.gc.ca/internet/ docs/20040302ce.pdf>.

Government of Canada. 2005a. 38th Parliament, 1st Session, Number 045, Standing Committee on Health, Evidence, Thursday, June 2, 2005. Retrieved January 31, 2017. <http://www.parl.gc.ca/content/hoc/ Committee/381/HESA/Evidence/EV1900397/HESAEV45-E.PDF>.

Government of Canada. 2005b. 38th Parliament, 1st Session, Number 051, Standing Committee on Health, Evidence, Thursday, October 27, 2005. Retrieved September 4, 2016. <http://www.parl.gc.ca/content/hoc/ Committee/381/HESA/Evidence/EV2067614/HESAEV51-E.PDF>.

Government of Canada. 2006a. 39th Parliament, 1st Session, Number 028, Standing Committee on Health, Evidence, Tuesday, November 21, 2006. Retrieved January 31, 2017. <http://www.parl.gc.ca/content/hoc/ Committee/391/HESA/Evidence/EV2528861/HESAEV28-E.PDF>.

Government of Canada. 2006b. House of Commons Debates, Official Report, Thursday, November 9, 2006. Retrieved September 4, 2016. <http://www.parl.gc.ca/content/hoc/House/391/Debates/080/HAN080-E.PDF>. 
Government of Canada. 2007. 39th Parliament, 1st Session, Number 036, Standing Committee on Health, Evidence, February 5, 2007. Retrieved September 4, 2016. <http://www.parl.gc.ca/content/hoc/Committee/391/HESA/ Evidence/EV2663348/HESAEV36-E.PDF>.

Guerrero, M., V.S. Mahadevan, P. Martinez-Clark, J. Rodes-Cabau, D. Ciaburriet, A. Greenbaum et al. 2015. "Transcatheter Mitral Valve Replacement with Balloon Expandable Valves in Native Mitral Valve Disease Due to Severe Mitral Annular Calcification: Results from the First Global Registry." Journal of the American College of Cardiology 66(15) (Suppl.): B291-92.

Gurvitch, R., D.A. Wood, E.L. Tay, J. Leipsic, J. Ye, S.V. Lichtenstein et al. 2010. "Transcatheter Aortic Valve Implantation: Durability of Clinical and Hemodynamic Outcomes beyond 3 Years in a Large Patient Cohort." Circulation 122(13): 1319-27. doi:10.1161/circulationaha.110.948877.

Hall-Findlay, E.J. 2011. "Breast Implant Complication Review: Double Capsules and Late Seromas." Plastic and Reconstructive Surgery 127(1): 56-66. doi:10.1097/prs.0b013e3181fad34d.

Hancock-Howard, R.L., C.M. Feindel, J. Rodes-Cabau, J.G. Webb, A.K. Thompson and K. Banz. 2013. “Cost Effectiveness of Transcatheter Aortic Valve Replacement Compared to Medical Management in Inoperable Patients with Severe Aortic Stenosis: Canadian Analysis based on the PARTNER Trial Cohort B findings." Journal of Medical Economics 16(4): 566-74. doi:10.3111/13696998.2013.770747.

Health Canada. 2006. Guidance for Industry: Keyword Index to Assist Manufacturers in Verifying the Class of Medical Devices. Retrieved September 2, 2016. <http://www.hc-sc.gc.ca/dhp-mps/alt_formats/hpfb-dgpsa/pdf/ md-im/keyword_motscles2-eng.pdf $>$.

Health Canada. 2007. Special Access Programme Issue Identification Paper. Retrieved September 2, 2016. <http:// www.hc-sc.gc.ca/dhp-mps/alt_formats/hpfb-dgpsa/pdf/acces/sap_pas_ident-eng.pdf $>$.

Health Canada. 2013. Medical Devices Bureau Annual Performance Report Fiscal Year 2012-13: April 1, 2012 through March 31, 2013. Ottawa, ON: Therapeutic Products Directorate.

Health Canada. 2014. Medical Devices Bureau Annual Performance Report: April 1, 2013 through March 31, 2014. Ottawa, ON: Therapeutic Products Directorate.

Health Canada. 2016. Guidance for Health Care Professionals on Special Access and Custom-Made Medical Devices. Retrieved September 2, 2016. <http://www.hc-sc.gc.ca/dhp-mps/alt_formats/hpfb-dgpsa/pdf/acces/ sap-md-dg-as-im-ld-eng.pdf>.

Health Canada and the Public Health Agency of Canada. 2014. Evaluation of the Medical Devices Program 1999-2000 to 2011-2012. Retrieved September 4, 2016. <http://www.hc-sc.gc.ca/ahc-asc/alt_formats/pdf/ performance/eval/medical_devices-materiels_medicaux-eng.pdf $>$.

Helton, T.J., S.R. Kapadia and E.M. Tuzcu. 2011. “Clinical Trial Experience with Transcatheter Aortic Valve Insertion." International Journal of Cardiovascular Imaging 27(8): 1143-54. doi:10.1007/s10554-011-9825-2.

Humpl, T., S. Furness, C. Gruenwald, C. Hyslop and G. van Arsdell. 2010. “The Berlin Heart EXCOR Pediatrics—the Sickkids Experience 2004-2008.” Artificial Organs 34(12): 1082-86. doi:10.1111/j.1525-1594.2009.00990.x.

Jilaihawi, H., T. Chakravarty, R.E. Weiss, G.P. Fontana, J. Forrester and R.R. Makkar. 2012. “Meta-Analysis of Complications in Aortic Valve Replacement: Comparison of Medtronic-Corevalve, Edwards-Sapien and Surgical Aortic Valve Replacement in 8,536 Patients." Catheterization and Cardiovascular Interventions 80(1): 128-38. doi:10.1002/ccd.23368.

Jilaihawi, H. and R. Ibrahim. 2010. “Complex Transcatheter Paravalvular Leak Repair." Catheterization and Cardiovascular Interventions 76(2): 194-97. doi:10.1002/ccd.22476.

Kadivar, K., L. Malloch, Y. Adonsou-Hoyi, D. Ng, S. Lavoie, K. Pulido et al. 2013. "Would CLSI M53-A have helped in the Diagnosis of HIV in Canada? Results of the Performance of Canadian Laboratories Participating in a Recent NLHRS Proficiency Testing Panel Containing HIV-1 Antigen Positive (Antibody Negative) and HIV-2 Samples." Journal of Clinical Virology 58(1): 303-05. doi:10.1016/j.jcv.2013.04.009.

Klepinski, R.J. 2006. "Old Customs, Ancient Lore: The Development of Custom Device Law through Neglect." Food and Drug Law Journal 61: 237-49. 
Kundu, S., M. Modabber, J.M. You, P. Tam, G. Nagai and R. Ting. 2011. “Use of PTFE Stent Grafts for Hemodialysis-Related Central Venous Occlusions: Intermediate-Term Results." Cardiovascular and Interventional Radiology 34(5): 949-57. doi:10.1007/s00270-010-0019-4.

Levac, D., H. Colquhoun and K.K. O’Brien. 2010. "Scoping Studies: Advancing the Methodology." Implementation Science 5(1): 1-9. doi:10.1186/1748-5908-5-69.

Lioupis, C., M.M. Corriveau, K.S. MacKenzie, D.I. Obrand, O.K. Steinmetz and C.Z. Abraham. 2012. "Treatment of Aortic Arch Aneurysms with a Modular Transfemoral Multibranched Stent Graft: Initial Experience." European Journal of Vascular and Endovascular Surgery 43(5): 525-32. doi:10.1016/j.ejvs.2012.01.031.

Mays, N., C. Pope and J. Popay. 2005. “Systematically Reviewing Qualitative and Quantitative Evidence to Inform Management and Policy-Making in the Health Field." Journal of Health Services Research and Policy 10(Suppl. 1): 6-20.

McAllister, P. and J. Jeswiet. 2003. "Medical Device Regulation for Manufacturers." Proceedings of the Institution of Mechanical Engineers, Part H: Journal of Engineering in Medicine 217(6): 459-67.

Mewhort, H.E., J.J. Appoo, G.L. Sumner, E. Herget and J. Wong. 2011. "Alternative Surgical Approach to Repair of the Ascending Aorta." Annals of Thoracic Surgery 92(3): 1108-10. doi:10.1016/j.athoracsur.2011.01.092.

Nietlispach, F., J. Leipsic, N. Wijesinghe, J.G. Webb and R.G. Carer. 2010. “First-in-Man use of a Tapered Endovascular Stent Graft for Treatment of Aneurysm after Coarctation Repair." Catheterization and Cardiovascular Interventions 76(7): 1035-40. doi:10.1002/ccd.22594.

O’Kelly, C.J., J. Spears, M. Chow, J. Wong, M. Boulton, A. Weill et al. 2013. “Canadian Experience with the Pipeline Embolization Device for Repair of Unruptured Intracranial Aneurysms." American Journal of Neuroradiology 34(2): 381-87. doi:10.3174/ajnr.a3224.

Osten, M.D., C. Feindel, M. Greutmann, K. Chamberlain, M. Meineri, B. Rubin et al. 2010. “Transcatheter Aortic Valve Implantation for High Risk Patients with Severe Aortic Stenosis Using the Edwards Sapien Balloon-Expandable Bioprosthesis: A Single Centre Study with Immediate and Medium-Term Outcomes." Catheterization and Cardiovascular Interventions 75(4): 475-85. doi:10.1002/ccd.22291.

Peters, W. 2002. “The Evolution of Breast Implants." Canadian Journal of Plastic Surgery 10(5): 223-36.

Pop, M., Y. Payette and M. Mansour. 2002. “Ultrasound Biomicroscopy of the Artisan Phakic Intraocular Lens in Hyperopic Eyes." Journal of Cataract and Refractive Surgery 28(10): 1799-803.

Purdham, D.M., M.K. Natarajan, D.T. Ko, E.A. Chen, C. Feindel and K. Kingsbury. 2012. “Baseline Characteristics and In-Hospital Outcomes of TAVI in Ontario: Data from the Cardiac Care Network of Ontario (CCN) TAVI Registry." Canadian Journal of Cardiology 28(5): S158.

Rao, V., J.F. Legare, R. Mac Arthur, J. Bashir, D. Freed, A. Cheung et al. 2013. "Multicenter Canadian Experience with the HeartWare HVAD." Journal of Heart and Lung Transplantation 32(4): S12.

Raymond, J., F. Guilbert and D. Roy. 2001. "Neck-Bridge Device for Endovascular Treatment of Wide-Neck Bifurcation Aneurysms: Initial Experience 1." Radiology 221(2): 318-26. doi:10.1148/radiol.2212010474

Regueiro, A., M. Bernier, G. O'Hara, K. O'Connor, J.-M. Paradis, J. Beaudoin et al. 2017. “Left Atrial Appendage Closure Initial Experience with the Ultraseal Device." Catheterization and Cardiovascular Interventions 90: 817-23.

Ricci, D.R., J. de Vries and R. Blanc. 2017. "Role of Preliminary Registry Data in Development of a Clinical Trial of An Innovative Device: A Small But Integral Piece of a Health Policy Initiative." Journal of Market Access \& Health Policy 5(1): 1283106.

Rodés-Cabau, J., E. Dumont, D. Doyle and J. Lemieux. 2010a. “Transcatheter Valve-in-Valve Implantation for the Treatment of Stentless Aortic Valve Dysfunction." Journal of Thoracic and Cardiovascular Surgery 140(1): 246-48. doi:10.1002/ccd.22168.

Saldana, J. 2012. The Coding Manual for Qualitative Researchers (2nd ed.). Thousand Oaks, CA: Sage Publishers. Sapp, J.L., C. Beeckler, R. Pike, R. Parkash, C.J. Gray, K. Zeppenfeld et al. 2013. “Initial Human Feasibility of Infusion Needle Catheter Ablation for Refractory Ventricular Tachycardia." Circulation 128(21): 2289-95. doi:10.1161/circlationaha.113.003423. 
Saw, J., P. Fahmy, P. DeJong, M. Lempereur, R. Spencer, M. Tsang et al. 2015. "Cardiac CT Angiography for Device Surveillance after Endovascular Left Atrial Appendage Closure." European Heart Journal-Cardiovascular Imaging 16(11): 1198-206. doi:10.1093/ehjci/jev067.

Saw, J., P. Fahmy, L. Azzalini, J.-F. Marquis, B. Hibbert, C. Morillo et al. 2017. “Early Canadian Multicenter Experience with WATCHMAN for Percutaneous Left Atrial Appendage Closure." Journal of Cardiovascular Physiology 28: 396-401.

Sinclair, A, X. Xie and M. McGregor. 2013. "Surgical Aortic Valve Replacement with the ATS Enable Sutureless Aortic Valve for Aortic Stenosis." Montreal, QC: Technology Assessment Unit (TAU) of the McGill University Health Centre (MUHC). Report no. 71.27p.

Snell, L., N. Baxter and J.L. Semple. 2008. "A Survey of Attitudes of Ontario Plastic Surgeons Leading up to the Return of Silicone Implants." Plastic and Reconstructive Surgery 122(5): 148e-49e.

Soon, J.L., J. Ye, S.V. Lichtenstein, D. Wood, J.G. Webb and A. Cheung. 2011. "Transapical Transcatheter Aortic Valve Implantation in the Presence of a Mitral Prosthesis." Journal of the American College of Cardiology 58(7): 715-21. doi:10.1016/j.jacc.2011.04.023.

Spear, S.L. and P. Hedén. 2007. "Allergan's Silicone Gel Breast Implants." Expert Review of Medical Devices 4(5): 699-708. doi:10.1586/174334440.4.5.699.

Stafinski, T., R. Deber, M. Rhainds, J. Martin, T. Noseworthy, S. Bryan and D. Menon. 2017. "DecisionMaking on New Non-Drug Health Technologies (NDTs) by Hospitals and Health Authorities in Canada." Manuscript submitted for publication.

Stein, R. and R. Stein. 2014. "Surgical Correction of Presbyopia: A Focus on New Techniques." Ophthalmology Rounds 10(6): 1-8.

Thomas, J. and A. Harden. 2008. "Methods for the Thematic Synthesis of Qualitative Research in Systematic Reviews." BMC Medical Research Methodology 8(1): 1. doi:10.1186/1471-2288/8/45.

Varvasovszky, Z. and R. Brugha. 2000. "A Stakeholder Analysis." Health Policy and Planning 15(3): 338-45.

Velasco-Sanchez, D., A. Tzikas, R. Ibrahim and J. Miró. 2013. “Transcatheter Closure of Perimembranous Ventricular Septal Defects." Catheterization and Cardiovascular Interventions 82(3): 474-79. doi:10.1002/ccd.24361.

Vilos, G.A. and F. Edris. 2007. “Second-Generation Endometrial Ablation Technologies: The Hot Liquid Balloons." Best Practice and Research Clinical Obstetrics and Gynaecology 21(6): 947-67. doi:10.1016/j. bpobgyn.2007.03.022.

Walker, M. J., W.A. Rogers and V. Entwistle. 2014. “Ethical Justifications for Access to Unapproved Medical Interventions: An Argument for (Limited) Patient Obligations." American Journal of Bioethics 14(11): 3-15. doi:10.1080/15265161.2014.957416.

Webb, J.G., M. Chandavimol, C.R. Thompson, D.R. Ricci, R.G. Carere, B.I. Munt et al. 2006. “Percutaneous Aortic Valve Implantation Retrograde from the Femoral Artery." Circulation 113(6): 842-50. doi:10.1161/ circulationaha.105.582882.

Webb, J.G., D.A. Wood, J. Ye, R. Gurvitch, J. Masson, J. Rodés-Cabau et al. 2010. “Transcatheter Valvein-Valve Implantation for Failed Bioprosthetic Heart Valves." Circulation 121(16): 1848-57. doi:10.1161/ circulationaha.109.924613.

Welp, M., A. de la Vega-Leinert, S. Stoll-Kleemann and C.C. Jaeger. 2006. “Science-Based Stakeholder Dialogues: Theories and Tools." Global Environmental Change 16(2): 170-81. doi:10.1016/j. gloenvcha.2005.12.002.

Wong, D.R., J. Ye, A. Cheung, J.G. Webb, R.G. Carere and S.V. Lichtenstein. 2010. “Technical Considerations to Avoid Pitfalls during Transapical Aortic Valve Implantation." Journal of Thoracic and Cardiovascular Surgery 140(1): 196-202. doi:10.1016/j.jtcvs.2009.07.081.

Yackel, D.B. and G.A. Vilos. 2004. “Thermablate EAS: A New Endometrial Ablation System.” Gynecological Surgery 1(2): 129-32. doi:10.1007/s10397-004-0011-6.

Zamorano, J.L., L.P. Badano, C. Bruce, K. Chan, A. Gonçalves, R.T. Hahn et al. 2011. “EAE/ASE Recommendations for the Use of Echocardiography in New Transcatheter Interventions for Valvular Heart Disease." Journal of the American Society of Echocardiography 24(9): 937-65. doi:10.1016/j.echo.2011.07.003. 